\section{SOI: $\underline{1.1 / \mathrm{TAS}}$ DOI: $10.15863 / \mathrm{TAS}$ International Scientific Journal Theoretical \& Applied Science}

p-ISSN: 2308-4944 (print) ｅ-ISSN: 2409-0085 (online)

Year: $2015 \quad$ Issue: 03 Volume: 23

Published: $30.03 .2015 \quad$ http://T-Science.org
Natalya Sergeyevna Klunko candidate of economic Sciences, Doctoral student, SaintPetersburg University of management and Economics, Department of Humanities, senior lecturer Interregional Institute of Economics and law at the IPA EURASEC, St. Petersburg, Russia chief-nata@yandex.ru

SECTION 31. Economic research, finance, innovation, risk management.

\title{
INNOVATION IS A LEADING FACTOR IN THE DEVELOPMENT OF THE RUSSIAN PHARMACEUTICAL INDUSTRY
}

\begin{abstract}
The article explores innovative component, which is defined by the author as a leading factor in the development of the Russian pharmaceutical industry. The goal set by the author, is to systematize our scientific views on innovative development of the pharmaceutical industry. The study is innovative component as a necessary component of development of pharmaceutical industry of Russia.

The practical value of the study lies in the fact that the author investigated the basic attributes inherent in innovative products, manufactured by the pharmaceutical industry. Identify opportunities and areas of innovation process management in pharmacy. Special attention is paid to the role of public participation in the development of innovative strategy of development of pharmaceutical industry in Russia.

The methodological basis of research is a systematic approach that gives the opportunity to consider innovative development as a set of factors that contribute to the introduction of various innovations in the activities of pharmaceutical companies.

The results of the study provide an opportunity to look at the problem of innovative development of national pharmacy as a process of constant updating various aspects of the pharmaceutical industry, based on the mechanism of program management.

Key words: innovation, pharmaceutical industry, factors, government, technology, project.

Language: Russian

Citation: Klunko NS (2015) INNOVATION IS A LEADING FACTOR IN THE DEVELOPMENT OF THE RUSSIAN PHARMACEUTICAL INDUSTRY. ISJ Theoretical \& Applied Science 03 (23): 101-108.

Soi: http://s-o-i.org/1.1/TAS*03(23)19 Doi: crossef http://dx.doi.org/10.15863/TAS.2015.03.23.19

\section{ИННОВАЦИОННАЯ СОСТАВЛЯЮЩАЯ - ВЕДУЩИЙ ФАКТОР РАЗВИТИЯ РОССИЙСКОЙ ФАРМАЦЕВТИЧЕСКОЙ ОТРАСЛИ}

Аннотация: В статье исследована инновационная составляющая, которая определена автором как ведущции фактор развития российской фармацевтической отрасли. Целью, которая поставлена автором, является систематизация имеющихся научных представлений относительно инновационного развития фармацевтического комплекса. Предметом исследования является инновационная составляющая как необходимая составляющая развития фармачевтического комплекса России. Практическое значение исследования заключается в том, что автором исследованы основные характерные признаки, присущие инновационной продукиии, выпускаемой фармацевтической отраслью. Определень возможности и направления управления инновачионным прочессом в фармации. Особое внимание уделено роли государственного участия в формировании инновационной стратегии развития фармацевтической отрасли в России. Методологическим основанием исследования является системный подход, дающий возможность рассматривать инновационное развитие как совокупность факторов, способствующих внедрению различных инновачий в деятельность фармацевтических предприятий. Результатьл исследования дают возможность взглянуть на проблему инновационного развития отечественной фармачии как на прочесс постоянного обновления различных сторон деятельности фармацевтической отрасли, основанный на механизме программно-целевого управления.
\end{abstract}

Ключевые слова: инновации, фармацевтическая отрасль, факторы, государство, технология, проект. 


\section{Введение.}

Структурные сдвиги, характерные для мировой экономики, являются следствием процесса глобализации, они вызывают поиск механизмов и инструментов развития всех сфер экономической деятельности, в том числе и фармацевтической промышленности, где основным производственным ресурсом становится информация и знания, а роль решающего фактора производства играют инновации.

Сущностью инновационной модели развития экономики, которая стала господствующей доктриной экономического роста в экономически и технологически развитых странах мира, а также странах с положительной динамикой техноэкономических изменений, является широкомасштабное введение в хозяйственный оборот через инновационные процессы таких продуктов интеллектуального труда, как передовые технологии, научнотехнические разработки и другие объекты прав интеллектуальной собственности научнотехнической сферы, а также внедрение эффективных организационно-управленческих решений с целью их коммерциализации или получения социально-экономического эффекта [8].

Изложение основного материала. Сейчас в мире существует не менее 5 тысяч лекарственных средств, которые проходили в свое время путь инновационности. Возникает логичный вопрос о целесообразности создания новых препаратов, что можно объяснить следующими причинами:

1) отсутствием безопасных и эффективных препаратов для лечения многих заболеваний (ВИЧ, вирус гепатита С, болезни Альцгеймера, Паркинсона и др.);

2) возникновением резистентности к имеющимся препаратам (ВИЧ, туберкулез и т.д.);
3) недостатками современной фармакотерапии (ежегодно в США около 100 тысяч пациентов умирает в результате побочного действия лекарств - это четвертое место среди самых распространенных причин смертности).

Следовательно, создание и внедрение инновационных препаратов позволяет, прежде всего, улучшить или изменить прогноз и в процессе протекания многих заболеваний, снизить смертность, а также существенно снизить затраты государства на лечение и реабилитацию пациентов, продлить их трудоспособный период. Яркими примерами, подтверждающими значение разработки принципиально новых лекарственных средств, является открытие в свое время антибактериальных медикаментов, которые кардинально снизили уровень смертности от инфекционных заболеваний, создание препаратов инсулина, лекарств для химиотерапии злокачественных новообразований. Существует и чисто меркантильная причина - фирма, владелец патента на оригинальный препарат, на протяжении 20 лет является монополистом на право его реализации.

Сегодня в разных странах мира на стадии разработки находится более 5 тысяч новых лекарственных средств, хотя следует признать, что большая их часть находится на этапе доклинических испытаний. Что касается наиболее востребованных показаний к ним, то в данной сфере следует указать на существенную трансформацию, речь идет о том, что если 10 - 15 лет назад значительная часть инновационных препаратов разрабатывалась с целью профилактики и лечения сердечнососудистых заболеваний, то в настоящее время основное количество инноваций сосредоточено в сфере онкологической помощи, активно разрабатываются и испытываются противоопухолевые средства, а также лекарственные средства, предназначенные для применения в неврологической практике, в частности при рассеянном склерозе, болезнях Альцгеймера и Паркинсона и других, неизлечимых пока еще недугах. Однако, учитывая значимость сердечнососудистых и цереброваскулярных заболеваний, как основных причин смертности населения в развитых странах, инновационные препараты этого сегмента продолжают широко внедрять в клиническую практику [11].

Проблемам организации инновационной деятельности в сфере фармацевтического производства посвящены исследования Е.Ю. Блиновой, Е.Л. Ковалевой, Е.Н. Мальченкова, А.О. Мамуто, А.С. Мятлика, Е.Г. Овчарова, М.О. Ольховской, А.А. Потапова, Н.В. Пятигорской, В.В. Семенова и т.д. Ученые указывают, что российская фармацевтическая отрасль, являющаяся одним из важнейших элементов отечественной экономики и системы социальной защиты населения, на сегодня представляет собой наукоёмкую отрасль, которая, безусловно, должна стать одним из наиболее высокоразвитых секторов российской экономики.

В тоже время, по мнению специалистов, инновационное развитие сдерживается следующими факторами: недостаточно эффективными экономическими механизмами государственной поддержки и стимулирования инновационной деятельности; отсутствием развитой инновационной инфраструктуры; не 
сформированной действующей системой защиты прав и интересов субъектов инновационной деятельности и участников процесса трансфера технологий [3].

Также специалисты обращают внимание на то, что сегодня отсутствуют действенные организационно-правовые механизмы и процедуры вовлечения научных организаций в инновационные процессы, подобное положение сложилось также и из-за недостаточности отечественного опыта использования объектов интеллектуальной собственности в хозяйственной деятельности фармацевтических предприятий [3].

Необходимо обратить внимание на то, что процесс создания инновационной продукции в фармацевтической отрасли имеет существенные отличия, которые выделяют отрасль среди других высокотехнологичных отраслей промышленности. Такими особенностями являются: стадийность инновационного процесса, который включает в себя ряд уникальных этапов, речь идет о биофармацевтических, доклинических, клинических исследованиях; для отрасли характерна длительность инновационного процесса, высокая стоимость научных разработок в сфере создания новых лекарственных средств; при этом, инновации в данной сфере имеют непродолжительный жизненный цикл, систему ценообразования, ориентированную на доступность инновационных лекарственных средств в сочетании с жесткой конкуренцией на внутреннем, а также на внешнем рынках, где основными игроками являются мощные мировые фармацевтические корпорации, которые являются лидерами инновационных процессов в области фармации.

Вместе с тем, на фармацевтическом рынке выделяют следующие основные подходы к определению инновационных лекарственных средств. Согласно первому, инновацией является лекарственное средство, которое базируется на новой молекуле, которая не идентифицируется как соль, эфир, изомер, и не является полиморфной модификацией ранее созданной субстанции, входящей в состав лекарственного препарата.

Другой подход определяет, что инновационные лекарственные препараты должны, в любом случае, иметь инновационный терапевтический эффект, либо создавать такие терапевтические преимущества, которые значительно повышают эффективность лечения, безопасность применения, удобство при использовании [5].
При этом, безопасность инноваций рассматривается как показатель, конкурирующий с эффективностью, то есть речь идет о том, что вне зависимости от показателей эффективности, каждый лекарственный препарат должен обладать достаточной степенью безопасности отсутствием побочных эффектов, создающих проблемы для здоровья пациента.

В то же время, Всемирной Медицинской Ассоциацией отмечается то, что эффективность, преимущества и риски нововведений должны анализироваться и сравниваться с лучшими препаратами, которые на сегодня имеются в арсенале медицины, и исключительно данных, которые получены на основе такого сравнения, и могут стать основанием для суждения относительно соотношения преимуществ и недостатков инновационных препаратов, а также об эффективности тех затрат, которые были понесены в связи с созданием нового лекарственного средства [12].

Следует сказать, что большинство исследователей _ - с специалистов фармацевтического дела, исходя из тех представлений, которые сложились в мировой фармацевтической промышленности, предлагают разделять лекарственные средства на несколько групп: в первую группу входят оригинальные лекарственные средства, во вторую - дженерики, в третью - иные лекарственные средства (фито-, гомеопатические лекарственные средства, комбинированные лекарственные средства) [3].

Что касается оригинальных лекарственных средств, принято выделять инновационные препараты и препараты-аналоги, которые, в свою очередь, подразделяются на препараты, имеющие признаки инноваций, и на препараты, имеющие признаки псевдоинновации. В то же время, признак инновационности не является постоянным, например препараты-аналоги в процессе их использования в медицинской практике могут раскрыть свой фармакотерапевтический потенциал, и на этом основании быть отнесенным к инновациям в базовой, либо в новой сфере практического использования. В тоже время, и те препараты, которые ранее считались инновационными, со временем, теряют свои позиции и переходят в разряд препаратов - аналогов.

В настоящее время в мире все чаще возникает озабоченность в связи с появлением в фармацевтической сфере псевдоинноваций, борьба с которыми составляет значительную часть защиты авторских прав в фармацевтической отрасли. Отголоски такой борьбы находимы в решениях судебных органов, например, недавно Верховный суд Индии отказал 
швейцарской фармацевтической компании Novartis выдать патент на противоопухолевый препарат Glivec на том основании, что он является модификацией уже известного химического соединения [10].

Некоторые специалисты, рассматривая инновации в сфере фармации, склонны также выделять фармацевтические, потребительские и медицинские критерии инновационности.

Фармацевтические характеристики включают в себя абсолютно новые либо модифицированные активные вещества, а также комбинации таких веществ. Инновационными могут считаться принципиально новые или усовершенствованные лекарственные формы, а также новые технологии, с помощью которых возможно получение активных веществ и лекарственных форм. Инновацией может считаться и способ доставки лекарственного вещества к биологической мишени (к органу, ткани, клетке, рецептору). Показатель повышенной биодоступности действующего вещества также относится к показателям инновационности лекарственного средства.

Потребительские характеристики инноваций могут включать в себя новое качество применения препарата (удобная лекарственная форма, возможности меньшей частоты приема, удобная дозировка, отсутствие либо меньшее количество побочных реакций и т.д., что ведет к улучшению качества лечения, улучшению качества жизни пациента).

Отдельные исследователи также выделяют инновационность потребительскую и производственную. Потребительская новизна представляет собой новые потребительские свойства, производственная новизна включает в себя инновационный механизм внедрения производства препарата, при этом, не имеет значения, что данный препарат выпускается иными предприятиями.

В зарубежной практике выделяют три группы инноваций, в основе которых лежит уровень новизны: базисные, инкрементальные (улучшающие) и модификационные инновации. [3]

Базисные инновации реализуют научнотехнические разработки и становятся основой формирования продуктов и технологий нового поколения, не имеющие аналогов.

Инкрементальные инновации не связаны с изменениями фармацевтических и фармакотерапевтических характеристик препаратов, однако, могут меняться такие параметры, как изменения дозировки, полученные данного препарата с помощью новой технологии, без изменения его свойств.
Модификационные инновации возникают тогда, когда потенциал инкрементальных исчерпан. Эти инновации представляют собой несущественные изменения продуктов, например, эстетические (цвет, форма и т.п.), а также несущественные технические изменения, не влияющие на эффективность лечения, применение препарата, на его параметры и свойства.

Таким образом, в фармацевтической промышленности подходы к определению инновационности могут быть разными и зависят от целей такого определения, речь в данном случае, идет о терапевтических, маркетинговых и производственных целях. В целом, абсолютной инновационностью обладают лекарственные препараты, которые обеспечивают совершенно новые, ранее неизвестные эффекты в фармакотерапии и повышают эффективность лечения пациентов, либо позитивно воздействуют на эффективность методов лечения, расширяют круг потребительских и производственных показателей.

Наличие у препарата терапевтических преимуществ является основной, но не единственной характеристикой их инновационности. Терапевтическое действие лекарственного средства зависит от механизма действия, фармакодинамических и фармакотерапевтических характеристик, которые, в свою очередь, прямо связаны с химической структурой действующего вещества. При этом, инновация в фармацевтической промышленности может быть определена как технико-технологический прогресс, который ведет к созданию совершенно нового продукта или снижению затрат на производство и увеличение терапевтической ценности существующих продуктов [13].

Несмотря на все известные достижения традиционных научных школ, «классическая» разработка новых лекарств в прошлом была во многом связана с успехами ученого, который доказывал положительный эффект применения тех или иных соединений, а не с систематическим и целенаправленным поиском. Сегодня известно, что содержимое ампул или блистеров проходит длительный путь синтетических и биологических исследований в лабораториях, который заканчивается регистрацией в регулирующих органах. В этой череде процессов особое значение придается всестороннему изучению эффективности и безопасности лекарственных средств, которые впервые появляются на рынке. Прежде, чем начать соответствующие исследования, нужно точно определить цель поиска, перспективы использования новых 
знаний и ресурсы, которые придется вложить в его получение.

Во время создания инновационного лекарственного средства основным критерием должно быть представление о его рациональном использовании. Это предполагает, что пациент получает лечение, которое удовлетворяет его клинические потребности, в дозах, отвечающих индивидуальным особенностям, в течение адекватного периода времени и по самой низкой цене. С этой целью исследователи и разработчики лекарственных средств еще на ранних этапах планирования должны считать своей главной задачей выявление заболеваний, в лечении которых существует острая потребность, и в отношении которых есть перспективы новых научно-обоснованных методов лечения.

Методология рационального оценивания будущего лекарственного средства должна предусматривать его место в спектре уже существующих препаратов. Стоит прогнозировать положительные и отрицательные стороны препарата и уже на раннем этапе исследования стремиться к расширению диапазона его применения, к профилактической направленности фармакотерапии на основе четких знаний клинических проявлений, осложнений и последствий заболевания [14].

Вторым компонентом, безусловно, является экономическая целесообразность разработки препарата, которая напрямую зависит от уровня финансирования здравоохранения, социальной сферы и благосостояния населения. Критериями выбора приоритетного и перспективного научноисследовательского направления должны быть: 1) острая медицинская необходимость; 2) возможность разработать новый или улучшенный курс лечения; 3) реальное прогнозирование ощутимой пользы от предложенного курса терапии [7].

На втором этапе из совокупности заболеваний выделяют направления, которые максимально отвечают следующим критериям: 1) медицинская потребность (оценка вариантов лечения); 2) коммерческая привлекательность (уровень заболеваемости, расходы на лечение); 3 ) возможность изучения заболевания и возможность получения о нем научнообоснованных данных.

Как только подходы определены, открывается возможность поиска вещества, которое бы имело желаемую активность. С помощью специальных методов конструирования, модельных технологий, а также применения принципов медицинской химии могут быть синтезированы, получены в чистом виде и описаны новые структуры на молекулярном уровне, которые могут быть использованы для создания инновационных лекарственных веществ.

Конструирование лекарств - один из самых первых, самых главных и важных моментов. Он наиболее трудоемкий и затратный. В исследовательской практике используют следующие методы: 1) разработка соединенийлидеров; 2) оптимизация соединения-лидера; 3) разработка лекарственного препарата. Соединение-лидер - это структурный прототип будущего лекарственного средства, то есть соединение, которое имеет определенную физиологическую активность, на основе которой создано лекарственное средство. В основном, этот статус вещества подтверждается систематическим скринингом, который достигается следующими методическими приемами: 1) исследованием в одном биологическом тесте достаточно большого количества соединений; 2) изучением нескольких соединений $\mathrm{c}$ оригинальной структурой во многих биологических тестах.

Результатом такого скрининга должно быть «попадание в цель», то есть нахождение соединения, которое проявляет должную физиологическую активность. С развитием компьютерных технологий и робототехники особое распространение получил так называемый тотальный скрининг, где в качестве прототипа используют уже известное лекарственное средство. С его помощью осуществляют одновременный автоматизированный и миниатюризированный анализ in vitro нескольких сотен и даже тысяч соединений в нескольких десятках биологических тестов. Разновидностью такого метода является комбинаторная химия, которая использует так называемые библиотеки, содержащие большое количество соединений, полученных однотипным методом. Эту смесь подвергают тотальному скринингу, после чего проводят идентификацию структур, проявляющих биологическую активность. Благодаря достижениям медицинской химии, молекулярной биологии и компьютерным технологиям в последнее время получило значительное развитие рациональное конструирование соединения-лидера. Он основывается на молекулярном моделировании или докинге, с помощью которого можно создавать новые химические соединения, имеющие сходство с рецептором.

Дальнейшая разработка включает все элементы внедрения препарата (создание технологического регламента синтеза субстанции, лекарственной формы, 
доклинические, клинические испытания, регистрация и маркетинг) [1].

Таким образом, инновация в фармацевтической промышленности может быть определена как технико-технологический прогресс, который ведет к созданию совершенно нового продукта или снижению затрат на производство и увеличение терапевтической ценности существующих продуктов.

Закономерно, что практически во всех развитых странах и тех, которые интенсивно развиваются, существуют программы государственной поддержки фармацевтической отрасли.

Например, в Европейском Союзе в рамках Седьмой рамочной программы по схеме государственно-частного партнерства был реализован проект «Инициатива инновационных лекарств» (The Innovative Medicines Initiative IMI), главная цель которого - способствовать совершенствованию процесса изобретения и разработки более безопасных и эффективных лекарственных средств (так, в рамках проекта, ученые получили доступ к конфиденциальным базам данных с результатами исследований крупных фармацевтических компаний). Общий бюджет проекта составил 2 млрд. евро [15].

В Российской Федерации также принята Государственная программа «Развитие фармацевтической и медицинской промышленности» на 2013-2020 годы [4].

Ответственным исполнителем Программы является Министерство промышленности и торговли Российской Федерации. Объем бюджетных ассигнований на реализацию Программы за счет средств федерального бюджета составляет 108 трлн. рублей. В этом документе проанализированы различные типы развития фармацевтической промышленности России: стагнационный, инерционный, инвестиционный. Наиболее перспективным был избран инерционно-инвестиционный сценарий. Он предусматривает, в первую очередь, обеспечение населения качественными и доступными по цене генерическими препаратами и параллельную разработку инновационных препаратов, а также их маркетинг.

После реализации Программы ожидается увеличение количества организаций, осуществивших технологические инновации в фармацевтической и медицинской отрасли; внедрение результатов интеллектуальной деятельности в сфере фармацевтической и медицинской промышленности; увеличение объема инвестиций в научные исследования, разработки, технологические инновации; переоснащение производства фармацевтической и медицинской продукции.

Хотя в России и принята соответствующая Программа, определенная часть фармацевтического сообщества считает, что она недостаточно эффективна. Так, производство лекарственных средств, а особенно иммунологических препаратов, которые, как правило, являются инновационными, требует значительных инвестиций, разработки и внедрения новейших технологий, закупки современного оборудования.

Поэтому, одним из путей увеличения объемов собственного производства является создание совместных предприятий и альянсов, проведение совместного маркетинга, расширение сотрудничества с производителями аналогичной продукции стран Таможенного союза ЕАЭС.

Кроме того, сейчас необходимо в полной мере задействовать механизмы государственночастного партнерства, в частности, в сфере производства продукции для диагностики и лечения социально опасных болезней.

Отметим, что как свидетельствует мировой опыт, формирование инновационной системы невозможно без активного участия государства, которое ставит перед научным сообществом задачу выявления перспективных научных и технологических направлений, которые могли бы стать основой долгосрочной научной и инновационной политики развития страны. Эффективное определение приоритетов в процессе создания оригинальных лекарственных средств зависит от полноты и точности анализа предмета исследования, действительных или потенциальных конкурентов, информации об уже имеющихся научных разработках [8].

Государство финансирует разработку до этапа, с которого дальнейшее финансирование продолжает бизнес, в отдельных случаях доводит разработку даже не до клинических испытаний, а до уровня привычной активности молекул. При этом, доклинические и клинические испытания проводятся с участием отечественных фармпроизводителей [9].

Еще один важный инструмент, который может быть задействован - это создание корпоративных венчурных фондов. Производители лекарств всегда испытывают нехватку средств и хорошо понимают необходимость создания инновационного портфеля. Уже сейчас есть прецеденты, когда они начинают инвестировать в наличие у препаратов определенных признаков инновационности. К каждой части средств, которые они вкладывают, государство могло бы добавлять еще и свою долю, это принятая практика. Привлекательность 
корпоративных венчурных фондов заключается в том, что они ждут результатов гораздо дольше, и как правило, венчурный фонд рассчитывает горизонт своей деятельности на уровне пяти лет, корпоративный вычурны фонд считает нормальным сроком - семь лет до получения практических результатов. Более того, если в силу обстоятельств реализация проекта складывается неудачно, корпоративный венчурный фонд, в отличие от обычного, переносит его положительные элементы в новый проект, то есть использует созданные активы рациональнее. Следовательно, только создавая соответствующие условия для финансирования научных разработок бизнесом и заинтересовывая бизнесменов брать на себя венчурные риски, можно достичь нужного уровня финансового обеспечения, а также эффективного использования средств научно-технических исследований [2].

Подобное совершенствование системы государственной поддержки развития фармацевтической промышленности, направленное на повышение технического уровня технологических процессов, положительно повлияет на общий уровень внутреннего производства.

Однако, вопросы развития отечественного производства лекарственных средств должны решаться не только путем предоставления государственной поддержки, установлением налоговых льгот и государственных гарантий, но и за счет рыночных рычагов регулирования, заинтересованности отечественного производителя в обеспечении конкурентоспособности собственной продукции и внедрения инноваций.

Для создания в России единой научнотехнологической цепочки «от молекулы к препарату» помимо целевых программ на государственном уровне целесообразно разработать соответствующий документ, в котором будут определены конкретные меры и механизмы, которые действительно будут способствовать их реализации.

Это может быть «платформа», «технология», «научное направление», однако, наиболее применимо название «проект» - термин, который чаще всего употребляют при выполнении научных и прикладных работ. Его реализация дает возможность для научно-технической деятельности, ограниченной во времени, направленной на достижение заранее определенного результата и создание уникального качественного продукта (лекарственного средства) в условиях дефицита ресурсов, установленного срока и наименьшего уровня риска.

По нашему мнению, «проект», как инструмент инновационного развития, консолидирует усилия специалистов всех необходимых направлений, является если не единственным, то, по крайней мере, эффективным для определения перспективных направлений конструирования оригинальных лекарственных средств, наиболее привлекательных для коммерциализации. Проект должен способствовать механизмам финансовой поддержки исследовательских и инвестиционных планов, а также координировать и контролировать научно-техническую разработку на всех его этапах - от идеи до внедрения. Выполнение проектов не должно прекращаться на стадиях научно-исследовательских, опытноконструкторских разработок или получения патента, любой проект должен быть доведен до логического завершения, а именно до создания инновационного лекарственного препарата, дошедшего до стадии практической коммерческой реализации.

\section{Вывод}

Как представляется автору статьи, используя данный подход, появляется возможность взглянуть на проблему инновационного развития отечественной фармации как на процесс постоянного обновления различных сторон деятельности фармацевтической отрасли, основанный на механизме программно-целевого управления проектной деятельностью, что открывает перспективы для дальнейших исследований проблемы инновационного развития фармацевтического комплекса Российской Федерации.

\section{References:}

1. Basalov SG (2000) Sovershenstvovanie otsenki i realizatsii innovatsionnoy politiki na predpriyatii (Na primere khimikofarmatsevticheskoy promyshlennosti): Dis.... kand. ekon. nauk. - Moscow, 2000, 158 p.
2. Bespalov SA (2004) Organizatsionnoekonomicheskiy mekhanizm privlecheniya investitsiy $\mathrm{v}$ naukoemkie otrasli promyshlennosti: na primere 
farmatsevticheskoy promyshlennosti: dis.... kand. ekon. nauk. - Moscow, 2004, 169 p.

3. Blinova EY (2010) Sovershenstvovanie sistemy upravleniya innovatsiyami v farmatsevticheskoy otrasli: avtoreferat dis.... kand. ekonom. nauk. - Sankt-Peterburg, 2010. 222 p. Available: http://refdb.ru/look/1974721pall.html (Accessed: 10.03.2015).

4. (2015) Gosudarstvennaya Programma Rossiyskoy Federatsii «Razvitie farmatsevticheskoy i meditsinskoy promyshlennosti» na 2013 - 2020. Available: http://pda.rlsnet.ru/Files/na/1.pdf (Accessed: 10.03.2015).

5. Il'chenko TE (2005) Farmakoekonomicheskiy analiz i nauchno-metodicheskoe obosnovanie vaktsinoprofilaktiki kleshchevogo entsefalita kak osnova obespecheniya strategii razvitiya farmatsevticheskogo predpriyatiya (na primere NPO "Virion"): avtoref. dis. kand. farm.nauk. Kursk, 2005, -26 p.

6. Kovaleva EL (2010) Sovershenstvovanie metodologicheskikh podkhodov $\mathrm{k}$ obespecheniyu kachestva i standartizatsii farmatsevticheskikh substantsiy i preparatov $\mathrm{v}$ lekarstvennoy forme «tabletki»: dis. ... dokt. farm. nauk. - Moskva, 2010, -430 p.

7. Mal'chenkov EN (2013) Razvitie marketingovogo potentsiala predpriyatiy farmatsevticheskoy promyshlennosti: dis. ... kand. ekon. nauk. - Penza, 2013, -223 p.

8. Mamuto AO (2013) Innovatsionnoe razvitie farmatsevticheskogo kompleksa na osnove mekhanizma gosudarstvenno-chastnogo partnerstva: dis. ... kand. ekon. nauk. - SanktPeterburg, 2013. -173 p.

9. Myatlik AS (2001) Metodicheskie podkhody k sovershenstvovaniyu gosudarstvennogo regulirovaniya farmatsevticheskoy promyshlennosti: dis.... kand. ekon. nauk. SPb., 2001. - 181 p.

10. Ovcharov EG (2005) Mirovaya farmatsevticheskaya promyshlennost': sovremennoe sostoyanie $\mathrm{i}$ tendentsii razvitiya $\mathrm{v}$ usloviyakh globalizatsii: dis.... kand. ekon. nauk. - Moscow, 2005. - 203 p.

11. Ol'khovskaya MO (2014) Innovatsionnye mekhanizmy upravleniya promyshlennost'yu (na primere farmatsevticheskoy otrasli): dis.... kand. ekon. nauk. - Moscow, 2014. -145 p.

12. Potapov AA (2011) Finansirovanie innovatsionnoy deyatel'nosti v farmatsevticheskom biznese: dis.... kand. ekon. nauk. - Sankt-Peterburg, 2011. -167 p.

13. Pyatigorskaya NV (2011) Issledovanie i metodologicheskie podkhody sozdaniya sovremennykh farmatsevticheskikh predpriyatiy Rossiyskoy Federatsii: dis. ... dokt. farm. nauk. - Moscow, 2011. -414 p.

14. Semenov VV (2004) Adaptatsiya promyshlennykh korporativnykh struktur Rossii $\mathrm{k}$ rynochnym usloviyam khozyaystvovaniya: $\mathrm{Na}$ primere gosudarstvennoy kompanii farmatsevticheskoy promyshlennosti: dis.... kand. ekon. nauk. - Moscow, 2004. -168 p.

15. (2015) Innovative Medicines Initiative. Available:

http://en.wikipedia.org/wiki/Innovative_Medici nes_Initiative (Accessed: 10.03.2015). 